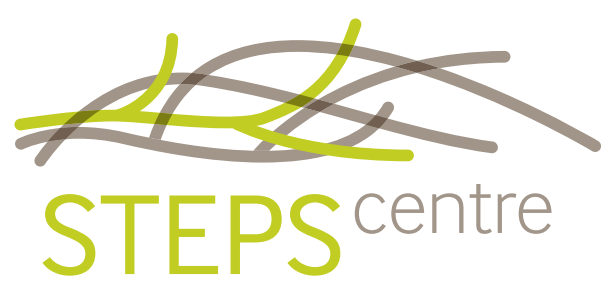

$\mathrm{E} \cdot \mathrm{S} \cdot \mathrm{R} \cdot \mathrm{C}$

ECONOMIC

\& SOCIAL

C OUNCI L

\title{
The Many Circuits of a Circular Economy
}

Ashish Chaturvedi, Jai Kumar Gaurav and Pragya Gupta
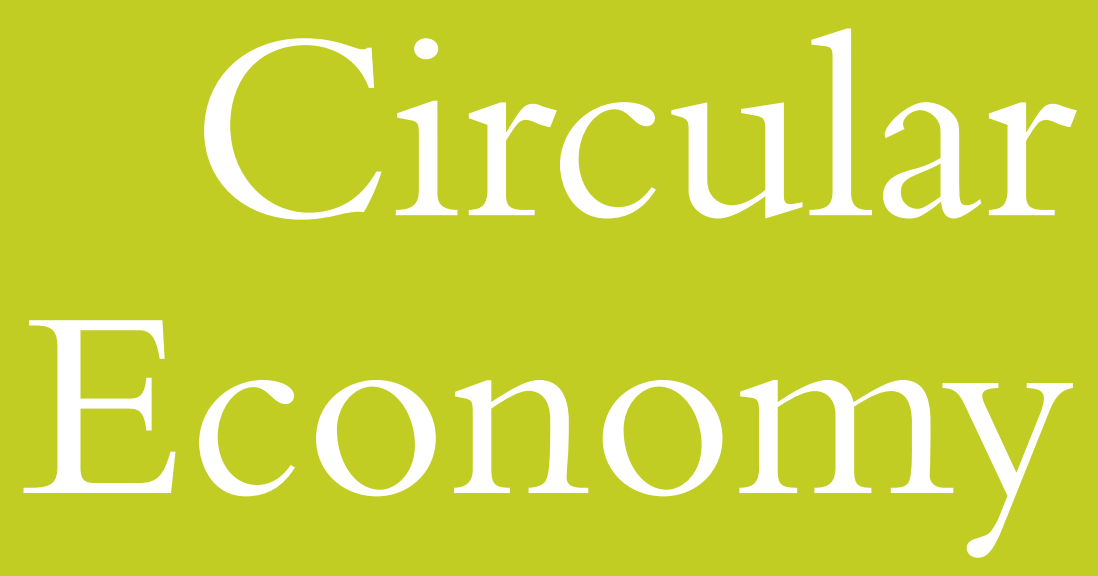


\section{The Many Circuits of a Circular Economy}

Rapid urbanisation in India has led to the development of large urban agglomerations. These urban agglomerations, with dense concentration of population and economic activity, cause significant environmental stresses.

The drawing up of resources and the generation of discharges are distributed in spaces within and beyond city boundaries. This inflow and outflow of resources suggests that cities are open systems with resource flows flowing in and out of city boundaries. A critical characteristic of such flows is that they are embedded in contestations in both material and discursive arenas. Actors with several, and conflicting interests, are affected by, and involved in managing, these flows of resources. The governance of these flows in the presence of such diverse and conflicting interests is critical to ensure that the most vulnerable actors involved in these flows have equitable access to resources as well as are not over-burdened by the degradation due to such flows in an out of cities. Over the last few years, the idea of a circular economy, driven by narratives of material scarcity and enhanced resource efficiency, is gaining traction around the globe. The focus of the existing literature on circular economy has largely been techno-managerial with a large emphasis on the role of big business in solving the problem. However, a close look at these flows of resources in India shows that a large part of these flows of resources happen outside the formal economy. Also, the focus of the existing literature on techno-managerial solutions ignores the multiple contestations in the material and discursive arenas. We believe that there is a limited focus on the politics of these flows in this literature. We focus on the case of closing material cycles in urban areas. We develop a conceptual framework that combines circular economy models and situates them in the variable power geometries of actors involved in these material flows in urban areas and beyond. With this conceptual framework, we examine the case of flow of materials in India (with a focus on Delhi). At the same time, we examine the impact of a focus on techno-managerial solutions on the vulnerable and marginal communities in urban areas.

\section{About the authors}

Ashish Chaturvedi is an Honorary Associate at the Institute of Development Studies (IDS) at the University of Sussex, and the Director of Climate Change at GIZ India. He specialises in climate change mitigation and adaptation, waste management, sustainable consumption and production, and environmental policy. His current focus is on policy and knowledge management aspects of climate change.
Jai Kumar Gaurav is a Climate Change and Environment sector professional with 9 years of diverse experience with NGOs, bi-lateral, multi-lateral organizations and private sector. He has completed his Masters in Climate Change and Development from IDS, University of Sussex. He currently works at GIZ in India.

Pragya Gupta is a financial sector professional and has completed her Masters in Globalisation, Business and Development at IDS, University of Sussex. She currently works at a Small Finance Bank in India which aims to increase financial inclusion for underbanked individuals and micro enterprises.

\section{About the STEPS Centre}

Today's world is experiencing rapid social, technological and environmental change, yet poverty and inequality are growing. Linking environmental sustainability with poverty reduction and social justice, and making science and technology work for the poor, have become central challenges of our times. The STEPS Centre (Social, Technological and Environmental Pathways to Sustainability) is an interdisciplinary global research and policy engagement hub that unites development studies with science and technology studies. We are developing a new approach to understanding and action on sustainability and development in an era of unprecedented dynamic change. Our pathways approach aims to link new theory with practical solutions that create better livelihoods, health and social justice for poor and marginalised people. The STEPS Centre is based at the Institute of Development Studies and SPRU (Science Policy Research Unit) at the University of Sussex, with partners in Africa, Asia and Latin America. We are funded by the ESRC, the UK's largest funding agency for research and training relating to social and economic issues.

\section{www.steps-centre.org.}

Follow us on Twitter astepscentre

\section{Other titles in this series include:}

Approach Pathways to sustainability: an overview of the STEPS Centre approach

1. Dynamics Dynamic Systems and the Challenge of Sustainability

2. Governance Understanding Governance: pathways to sustainability

3. Designs Empowering Designs: towards more progressive appraisal of sustainability

4. Agriculture Agri-Food System Dynamics: pathways to sustainability in an era of uncertainty

5. Health Health in a Dynamic World

6. Water Liquid Dynamics: challenges for sustainability in water and sanitation

For more STEPS Centre publications visit:

www.steps-centre.org/publications 


\section{The Many Circuits of a Circular Economy}

Ashish Chaturvedi, Jai Kumar Gaurav and Pragya Gupta 
Correct Citation: Chaturvedi, A., Gaurav, J. K. and Gupta, P. (2017) The Many Circuits of a Circular Economy, STEPS Working Paper 94, Brighton: STEPS Centre

(C) STEPS 2017

Some rights reserved - see copyright license for details

ISBN: 978-1-78118-367-0

\section{Acknowledgements}

The authors would like to thank Hubert Schmitz, Emeritus Fellow and Patrick Schroeder, Research Fellow, both at the Institute of Development Studies, University of Sussex, for their helpful reviews of this working paper. Thanks also to Jan Boyes for her excellent copyediting skills.

For further information please contact: STEPS Centre, University of Sussex, Brighton BN1 9RE

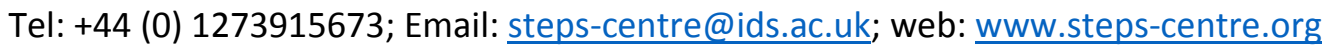

STEPS Centre publications are published under a Creative Commons Attribution - Non-Commercial No Derivative Works 3.0 UK: England \& Wales Licence (http://creativecommons.org/licenses/by-ncnd/3.0/legalcode)

Attribution: You must attribute the work in the manner specified by the author or licensor.

Non-commercial: You may not use this work for commercial purposes.

No Derivative Works: You may not alter, transfer, or build on this work.

Users are welcome to copy, distribute, display, translate or perform this work without written permission subject to the conditions set out in the Creative Commons licence. For any reuse or distribution, you must make clear to others the licence terms of this work. If you use the work, we ask that you reference the STEPS Centre website (www.steps-centre.org) and send a copy of the work or a link to its use online to the following address for our archive: STEPS Centre, University of Sussex, Brighton BN1 9RE, UK (steps-centre@ids.ac.uk).

\section{cc) creative}




\section{Contents}

Contents …

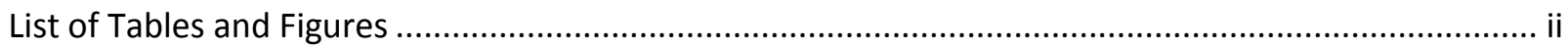

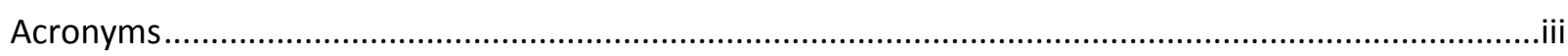

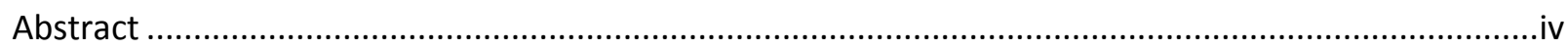

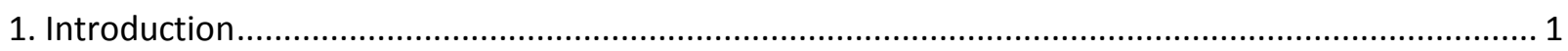

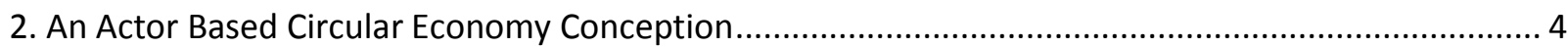

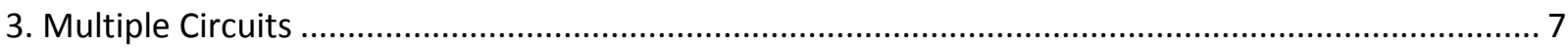

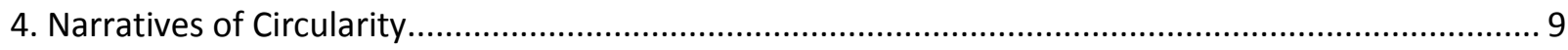

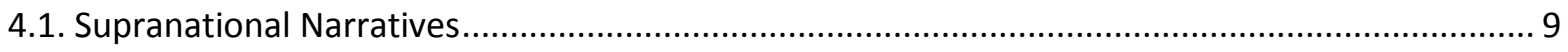

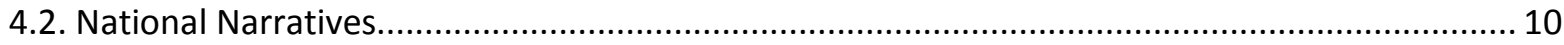

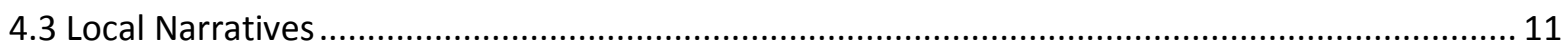

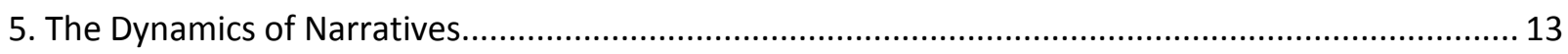

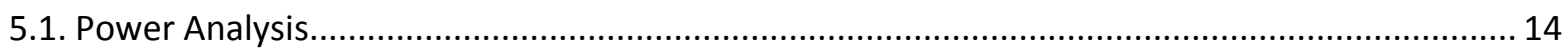

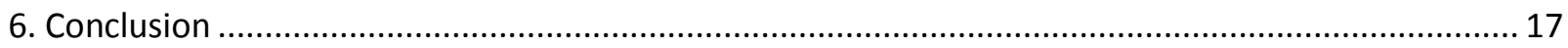

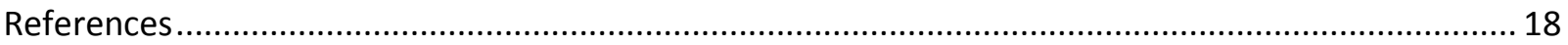




\section{List of Tables and Figures}

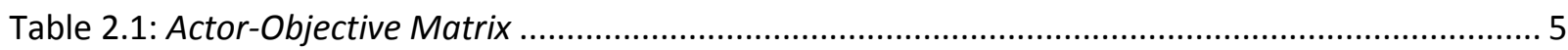

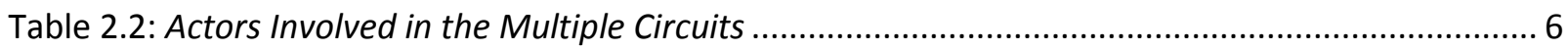

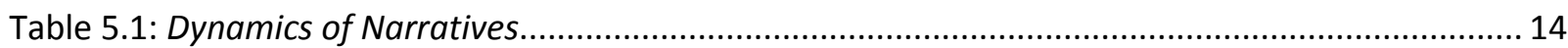

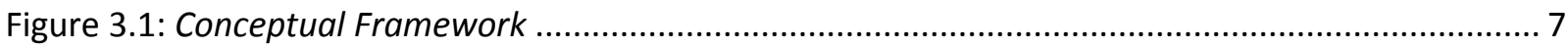

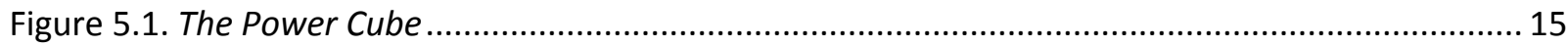




\section{Acronyms}

CSE

EMF

EU

GAIA

GIZ

MoUD

MSW

NGO

WBCSD

WEF
Centre for Science and Environment

Ellen MacArthur Foundation

European Government

Global Alliance for Incinerator Alternatives

German Corporation for International Cooperation

Ministry of Housing and Urban Affairs

Municipal Solid Waste

Non Governmental Organisations

World Business Council for Sustainable Development

World Economic Forum 


\begin{abstract}
Rapid urbanisation in India has led to the development of large urban agglomerations. These urban agglomerations, with dense concentration of population and economic activity, cause significant environmental stresses.

The drawing up of resources and the generation of discharges are distributed in spaces within and beyond city boundaries. This inflow and outflow of resources suggests that cities are open systems with resource flows flowing in and out of city boundaries. A critical characteristic of such flows is that they are embedded in contestations in both material and discursive arenas. Actors with several, and conflicting, interests are affected by, and involved in managing, these flows of resources. The governance of these flows in the presence of such diverse and conflicting interests is critical to ensure that the most vulnerable actors involved in these flows have equitable access to resources as well as are not over-burdened by the degradation due to such flows in an out of cities. Over the last few years, the idea of a circular economy, driven by narratives of material scarcity and enhanced resource efficiency, is gaining traction around the globe. The focus of the existing literature on circular economy has largely been techno-managerial with a large emphasis on the role of big business in solving the problem. However, a close look at these flows of resources in India shows that a large part of these flows of resources happen outside the formal economy. Also, the focus of the existing literature on techno-managerial solutions ignores the multiple contestations in the material and discursive arenas. We believe that there is a limited focus on the politics of these flows in this literature. In this paper we focus on the case of closing material cycles in urban areas. We develop a conceptual framework that combines circular economy models and situates them in the variable power geometries of actors involved in these material flows in urban areas and beyond. With this conceptual framework, we then examine the case of flow of materials in India (with a focus on Delhi). At the same time, we examine the impact of a focus on techno-managerial solutions on the vulnerable and marginal communities in urban areas.
\end{abstract}




\section{Introduction}

Rapid urbanisation in India has led to the development of large urban agglomerations. These urban agglomerations, with a dense concentration of population and economic activity, cause significant environmental stresses. The stresses emanate because cities act both as sinks of resources as well as generators of environmental degradation. First, they draw resources to meet the demands (for water, energy, buildings, urban infrastructure and food) of their inhabitants. The provisioning of such resources creates environmental degradation at the origin of these flows of resources. Second, cities are significant generators of (resources embedded in) effluents and discharges (to water, soil and air) that lead to environmental degradation within their boundaries and beyond.

The first characteristic of such flows is that they are spatially distributed. The drawing up of resources and the generation of discharges are distributed in spaces within and beyond city boundaries. This inflow and outflow of resources suggest that cities are open systems with resource flows flowing in and out of city boundaries. It must be pointed out that while the flows cut across city boundaries, there is an imbalance between the inflows and outflows - cities draw the benefits from the inflows of resources but cause significant damage from the outflows.

The second characteristic of such flows is that they are embedded in contestations in both material and discursive arenas. Actors with several, and conflicting interests are affected by and involved in managing these flows of resources. The governance of these flows in the presence of such diverse and conflicting interests is critical in ensuring that the most vulnerable actors involved in these flows have equitable access to resources as well as not being disproportionately over-burdened by the degradation due to such flows in an out of cities.

The current trajectory of these material flows, in and out of large cities in India, is clearly unsustainable, with around 62 Million Tonnes of municipal solid waste (MSW) generated per year across cities in India (CSE, 2016) most of which is landfilled, leading to ground water contamination, air pollution and health hazards. There is rapid growth in environmental degradation with its impact felt within cities as well as in peri-urban areas. At the same time, there are several contestations in the governance of these flows. It is clear that sustainable urbanisation would need to take into account the spatial distribution of these flows of materials as well as the contestations of these flows in the material and discursive arenas.

A potential solution, especially to correct the spatial distribution of these flows, is to focus on closing these material cycles. There is a long tradition of research in natural, as well as social, science about circular flows of materials. However, over the last few years, the idea of a circular economy, driven by narratives of material scarcity and enhanced resource efficiency, is gaining traction around the globe. For instance, according to a joint report by the Ellen MacArthur Foundation (EMF) and the World Economic Forum (WEF):

A circular economy is an industrial system that is restorative or regenerative by intention and design. It replaces the end-of-life concept with restoration, shifts towards the use of renewable energy, eliminates the use of toxic chemicals, which impair reuse and return to the biosphere, and aims for the elimination of waste through the superior design of materials, products, systems and business models.

World Economic Forum 2014

As the definition above suggests, the focus of a large part of the existing literature on the circular economy has largely been techno-managerial with an emphasis on the role of big business in solving the problem. Further, the existing literature largely focuses on the technical definitions of the 'what' of closing material cycles. For instance, reports from the EMF present a framework where both technical 
and biological nutrient could be circularly managed. The various steps involved in closing material cycles are defined in great detail. At the same time, there are illustrations of each of these through case studies. The examples of circular economy approaches provided in the existing literature also focus on either niche interventions or of large corporations closing material cycles within the value chains they control. As a result of the focus on niche examples, it seems that large corporations would be able to influence significantly not only the conceptualisation but also lead the transformation to the circular economy.

We believe that if the transformation to a circular economy has to happen at scale and led by businesses (as envisaged in most of the existing literature), it is not clear how businesses that gain from current models of make-use-throw would suddenly make the transformative leap. We also believe that such conceptualisation creates a limited understanding of the processes that contribute to closing material cycles and has the potential to lead to sub-optimal outcomes. For instance, due to the presence of the large informal sector in managing waste in most urban areas, it is critical to think about a framework that also includes these actors. Also, the roles of government and policymakers are largely ignored in the current framework. Further, by focusing on the value chains of large businesses, there is limited attention to potential approaches at the level of a city, let alone a country.

In this paper, rather than focusing on particular value chains, we focus on the case of closing material cycles in urban areas. We have developed a conceptual framework that combines circular economy models, and situates them in the variable power geometries of actors involved in these material flows in urban areas and beyond. We then describe the narratives on waste management that exist at the supranational, national and local level. While characterising the national and local narratives, we focus on India and a large Indian city (Delhi) respectively. At the same time, we examine the impact of a focus on techno-managerial solutions on the vulnerable and marginal communities in urban areas. We believe that this paper provides a new and much needed framework for analysing urban waste management, emphasises the need for such a framework, brings out its key components and illustrates its relevance for India.

The paper brings together two analytical shifts. The first shift is from technical to political analysis. As most of the circular economy narrative is about such things as nutrients, metals rather than people, our framework shows how people can be brought at the centre of circular economy. The second shift is from single to multi-scale analysis. The proposed framework shows that the narratives at the local, national and international level interact with each other in several ways, on occasions reinforcing each other while on others contradicting each other. Such dynamics between the narratives have material consequences, not only on the lives of people who are involved in waste management but also on the formulation of policies that are driven by dominant narratives. Our analysis suggests that the development of dominant narratives is a result of the contestations in the discursive arena and as a result it is critical that the framework relies on multi-scale analysis.

This paper shows that building an economy which is both more circular and more equitable requires understanding the actors that play a role in these multiple circuits and understanding their priorities. It shows that these priorities are diverse and often in conflict with each other, that such conflicts arise in particular over the role of the informal sector, that there is a potential for building new alliances adopting less wasteful and more equal policies, and that identifying co-benefits is central for such an approach.

In what follows, we describe the aspects of a circular economy with a focus on the actors who are involved in closing material cycles. The focus on an actor-centric approach also allows us to develop in subsequent sections the several narratives that are associated with the move towards closing material cycles. Section 3 presents the conceptual framework and Section 4 presents the narratives at different levels. In section 5 we describe the dynamics between the narratives at different levels and we conclude in Section 6. 


\section{An Actor Based Circular Economy Conception}

The transformation from a linear to a circular economy would require not only environmental but also social and economic restructuring of production and consumption patterns. Such systemic restructuring would involve several actors. Some of these actors are likely to benefit while others are likely to lose from such restructuring. As a result, some actors are likely to block, while others are likely to drive, the transformation to a circular economy. At the same time, the actors who are likely to benefit from the transformation to a circular economy have different objectives and priorities and, as a result, would drive for the transformation to occur in a manner that allows them to appropriate the gains from the transformation. Therefore it is critical to develop an actor-centric framework for analysing the transformation from a linear to a circular economy.

A starting point for the transformation to a circular economy is effective waste management. In most developed countries the policy towards closing material cycles have largely emanated as a reform of the waste management policies. Policies aimed at closing material cycles are inextricably linked to the reformulation of the existing waste management policies. In India the recently amended waste management rules are also based on the waste management hierarchy. However, distinct from most developed countries, a large part of the waste management in developing countries is handled by the informal sector. Therefore a critical uncertainty that emanates from the efforts at closing the material cycles arises regarding the role of the informal sector in waste management. Does the transition to a circular economy marginalise the informal sector, or does it use the strengths of the informal sector for cost effective solutions? This question is at the heart of a just and equitable transformation as well as the focus of any actor centric framework.

The informal sector, in spite of its informality, is well organised. Also, the services provided are efficient as well as convenient - two necessary characteristics of waste management systems globally. In addition to recycling and waste management service at low cost, the informal sector is able to provide employment to urban poor in labour-intensive processes for collection, manual segregation and recycling (Agarwal et al. 2002). Despite the low cost recycling and waste management service, as well as the employment creation potential, of the informal sector it is discouraged due to considering the potentially negative health and environmental impact of unsafe recycling practices (Annamalai 2015). Specifically in the case of e-waste, environmentally sound recycling and enhanced resource recovery are the key reasons for establishing a formal waste management system in developing countries (Arora et al. 2010: 91). This creates a dichotomy in the broader narrative of recycling and closing the loop with stakeholders divided between formal versus informal, high-tech versus low-tech and large private sector versus small or cooperatives of individual informal recyclers and waste managers.

Due to the complexity and dynamics involved in different circuits of circular economy, each suggesting different pathways to different sustainabilities, it is argued that 'lock-in' to a particular powerful narrative and associated pathway can exclude others. Therefore, there is a need to 'open up' and make space for more plural and dynamic sustainabilities, challenging dominant narratives and pathways, and highlighting alternatives, including those reflecting the perspectives and priorities of poor and marginalised people (STEPS Briefing undated). The STEPS 'pathways approach' developed by Leach et al. (2010: ix) provides a useful analytical tool to understand the complex and dynamic narratives to circular economy and identify the varied pathways. As noted by the authors (ibid: 68) critical to evaluating alternative pathways is the need to emphasise those particular pathways which, 'recognise and support the goals of people who are struggling to move out of poverty and marginalisation'. Applying this perspective to the circuits of circular economy, the informal enterprises engaged in repair, second-hand trade and recycling of waste gain particular importance in the scenario where they are compared to formal sector recyclers. As noted by Leach et al. (2010: 56) pathways exist in an environment of conditional plurality, i.e. the multiple approaches and solutions are dependent on the 
varied framings of problems. Thus, identification of the varied actors, their networks and their objectives is crucial to understand their specific framings. The actor objective matrix developed by Schmitz (2012: 3) and used by Chaturvedi et al. (2015a: 12) is used to identify and summarise the objectives of the key actors in e-waste management (see Table 2.1).

Table 2.1: Actor-Objective Matrix

\begin{tabular}{|l|l|l|l|l|l|l|}
\hline Objective & Actor 1 & Actor 2 & Actor 3 & Actor 4 & Actor 5 & Actor 6 \\
\hline Environment Protection & & & & & & \\
\hline $\begin{array}{l}\text { Livelihoods and } \\
\text { Employment generation }\end{array}$ & & & & & & \\
\hline Resource Value of Waste & & & & & & \\
\hline $\begin{array}{l}\text { Waste Minimisation } \\
\text { (reduce and reuse) }\end{array}$ & & & & & & \\
\hline $\begin{array}{l}\text { BoP Access to goods and } \\
\text { services }\end{array}$ & & & & & & \\
\hline $\begin{array}{l}\text { Only concern is to get the } \\
\text { waste out of sight. } \\
\text { Removed in whatever } \\
\text { way. }\end{array}$ & & & & & & \\
\hline
\end{tabular}

Source: Adapted based on Wilson (2007), Schmitz (2012) and Chaturvedi et al. (2015a)

As noted by Chaturvedi et al. (2015a: 12), it is however important to note that actors may share common goals even though the priorities and ranking among the different objectives might vary. This matrix above highlights both areas of collaboration and conflict that can also provide inputs for determination of opportunities for opening pathways. The matrix enables an analysis of the different narratives to circular economy. However, power dynamics both within and among actors can also influence the choice of pathways. Leach et al. (2010: 65-66) note the dual effect of 'governance', which is defined by the authors as 'the intersection of power, politics and institutions', on both the framing of problems as well as the choice of solutions/pathways. The barriers to informal sector pathway based on power dynamics and politics can be analysed using the power-cube framework developed by Gaventa (2006). The relative power and influence of various actors is thus analysed across spaces (closed, invited, created), levels (local, national, global) and forms (visible, invisible and hidden) of power. Gaventa (2006: 26) notes that analysis of spaces should seek to understand how the spaces were created, who created them and what the engagement terms are. With regard to the levels of power, it is essential to note the different locations of power to identify spaces for engagement within each. Also while each level - local, national, global - presents opportunities for participation, interconnections and linkages among the actors at different levels is essential for effective change. Batliwala (2002, cited in Gaventa 2006: 28) also notes the importance of, 'vertical links between those organisations doing advocacy at an international level, often led or supported by international NGOs, with those working to build social movements or alternative strategies for change at the more local levels'. Similarly the study of different forms of power aims to identify visible and invisible manifestations of power that influence the values and narratives of different actors. Leach et al. (2010:169) also note that a pathways approach is not aimed only to assess the varied options but also to focus on building pathways that are marginalised. This involves opening up policy processes and spaces, including conceptual, bureaucratic, invited, popular and practical spaces (Leach et al: 138). Additionally, different forms of citizen engagement and mobilisation, ranging from protests to media and legal system engagement, may be used to broaden pathways. Equally important for effective change, is the development of alliances within and across different actors and levels as highlighted by Gaventa (2006: 28). This is also noted by Chaturvedi et al. (2015a: 28) as crucial for sustaining pathways. 
The varied actors involved in the different circuits of circular economy can be divided into government, business and civil society or Non Governmental Organisations (NGO) at local, national and supranational level. These actors have different levels of influence and can have aligned or conflicting interests. Table 2.2 below presents stakeholders in repair, refurbish, recycle and incineration circuits.

Table 2.2: Actors Involved in the Multiple Circuits

\begin{tabular}{|l|l|l|l|}
\hline $\begin{array}{l}\text { Repair and reuse } \\
\text { circuit }\end{array}$ & $\begin{array}{l}\text { Business } \\
\text { Small businesses, } \\
\text { traders of second hand } \\
\text { products }\end{array}$ & $\begin{array}{l}\text { Local Government } \\
\text { mostly }\end{array}$ & $\begin{array}{l}\text { Government } \\
\text { Level NGOs few } \\
\text { international NGOs } \\
\text { like GAIA }\end{array}$ \\
\hline Refurbishing Circuit & $\begin{array}{l}\text { Private Medium Sized } \\
\text { companies }\end{array}$ & $\begin{array}{l}\text { Local and National } \\
\text { Government }\end{array}$ & $\begin{array}{l}\text { Local and National } \\
\text { NGOs promoting } \\
\text { refurbishing }\end{array}$ \\
\hline Formal Recycling & $\begin{array}{l}\text { Large Corporations } \\
\text { with agreement with } \\
\text { formal recyclers }\end{array}$ & $\begin{array}{l}\text { Local, National and } \\
\text { Supra-National } \\
\text { governments like UN, } \\
\text { European Union }\end{array}$ & $\begin{array}{l}\text { NGOs like World } \\
\text { Economic Forum, EMF } \\
\text { etc. }\end{array}$ \\
\hline $\begin{array}{l}\text { Informal Recycling } \\
\text { Circuit }\end{array}$ & $\begin{array}{l}\text { Small informal sector } \\
\text { recyclers }\end{array}$ & $\begin{array}{l}\text { Local governments } \\
\text { and national } \\
\text { governments }\end{array}$ & $\begin{array}{l}\text { NGOs at local and } \\
\text { national level in } \\
\text { addition to few } \\
\text { international NGOs } \\
\text { like GAIA }\end{array}$ \\
\hline Incineration Circuit & $\begin{array}{l}\text { Waste management } \\
\text { companies charging } \\
\text { for waste incinerated } \\
\text { to generate power or } \\
\text { reduce volume of } \\
\text { waste }\end{array}$ & $\begin{array}{l}\text { Socal, National and } \\
\text { governments like UN, } \\
\text { European Union. }\end{array}$ & $\begin{array}{l}\text { NGOs such as World } \\
\text { Economic Forum, EMF } \\
\text { etc. }\end{array}$ \\
\hline
\end{tabular}

Source: Author's own 


\section{Multiple Circuits}

It is clear from the discussion above that there is a diversity of actors operating at different levels that are involved in closing material cycles. The stakeholders involved in the circular economy can be categorised into Government, Business and Civil Society organisations and NGOs. While stakeholder groups have individual interests and agenda, there is active alliance building for promoting a common narrative to influence policy and implementation. The alliances can range from local level to supranational level. For instance the WEF, representing multi-national firms (Businesses), is working with United Nations, the European Union (EU) (Governments) and Ellen MacArthur Foundation (NGOs) to promote the idea of a private sector, technology led, circular economy approach (one of the many circuits of the circular economy) influencing national and local level government. Another approach to circular economy involving informal sector for local level repair and recycling (another circuit of the circular economy) has the alliance of local and national NGOs (such as Chintan, Centre for Science and Environment (CSE)) and international NGOs (such as the Global Alliance for Incinerator Alternatives (GAIA)).

It is also evident that there are different circuits of circular economy involving different set of actors and there is a need to better understand the dynamics within the circuits as well as how they interact with the policy landscape. The conceptual framework presented below highlights how the circular economy has local, national and supranational level dimensions through the flow of raw materials, products and waste generation within a country and between countries through exports and imports.

Figure 3.1: Conceptual Framework

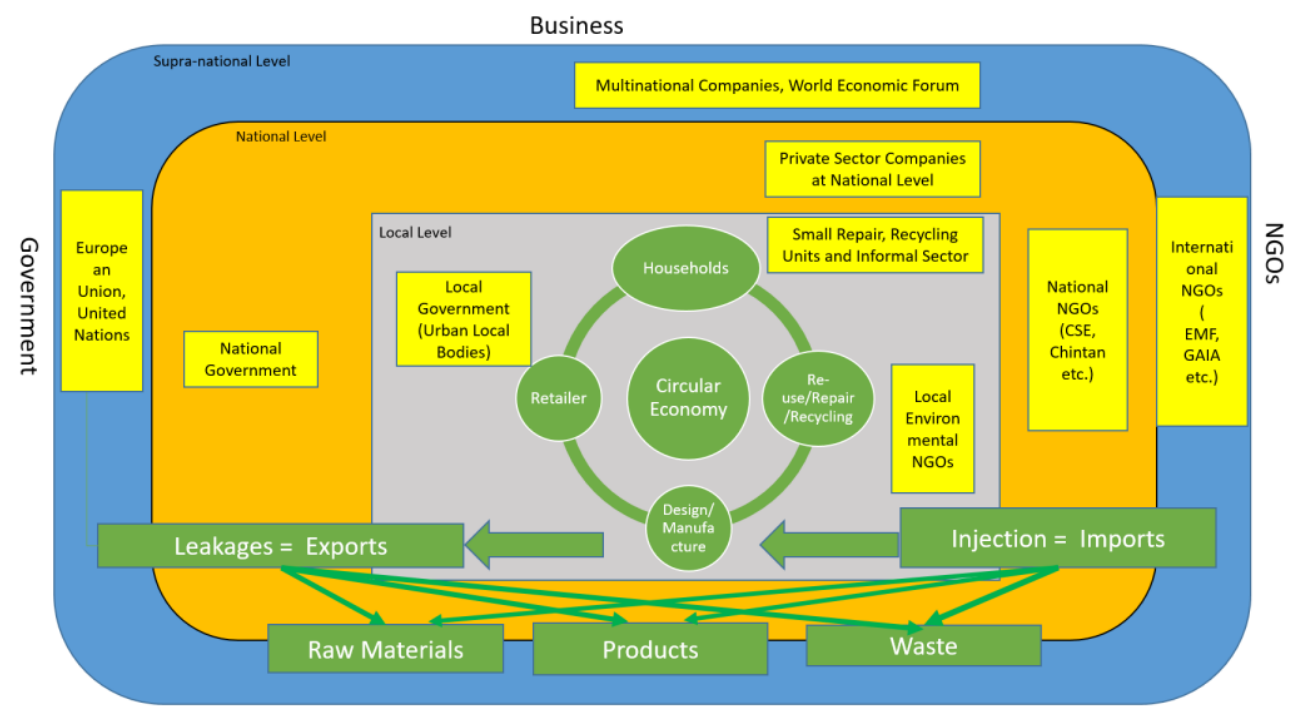

Source: Author's own

The framework above suggests that due to the flows of materials between cities and nations, closing material cycles cannot happen within local or national boundaries. The flows of materials across the local and national boundaries implies that, in a material sense, cities as well as nations are open systems (Chaturvedi and McMurray 2015). At the same time, as there are actors from the private sector, civil society as well as the state operating at different levels, there is a constant interaction between the narratives espoused by these actors. All the actors have a certain set of objectives and priorities as well as a conception of the transformation to a circular economy. This interaction between the actors in the material and discursive arena leads to the development of alliances between the actors who coalesce around shared conceptions of the future as well as shared objectives. 


\section{Narratives of Circularity}

In this Section, we characterise the narratives that have emerged at different scales on the transformation to a circular economy. The aim is to identify the actors and their attempts to characterise the transformation to a circular economy. The narratives reflect the priorities and interests of the actors while at the same time reflect the conception of economic, social and political leanings of the actors. We classify these narratives according to scale because of the scope of influence of the actors who espouse the narratives. While this classification might seem occasionally restricted as these actors occupy and influence several scales simultaneously, the classification according to scale allows for analytical tractability. Also, in most cases the restriction is also real as it reflects the priorities of the actors and their sphere of influence.

\subsection{Supranational Narratives}

The narratives at the supranational level are largely based on the premise that the circular economy is critically linked to the sustainability of the planet. For instance, the EMF states that a circular economy is one that is restorative and regenerative by design, and which aims to keep products, components and materials at their highest utility and value at all times, distinguishing between technical and biological cycles. EMF's 'Circular Economy 100' is an innovation programme established to enable organisations to develop new opportunities and realise their circular economy ambit, which is claimed to be a $€ 1.8$ trillion circular economy opportunity. EMF has published several studies focusing on the role of mostly large private sector organisations in achieving circular economy objectives building on technology and private capital (EMF 2017).

On Similar lines the WEF's 'System Initiative on Shaping the Future of Environment and Natural Resource Security' focuses on Circular Economy, Tropical Forests, Water Security, Oceans and Climate Change Solutions (WEF 2017). The initiatives such as those of WEF, MacArthur Foundation (and others) with significant private sector involvement, aim to influence policy at national and international level.

At the same time, these narratives build on notions of resource efficiency, resource security and environmental considerations. For instance, the EU focused on a resource efficiency and resource security agenda as the cornerstone of the transformation to a circular economy. Of course, these considerations also have co-benefits for the economy and society but those benefits are not at the centre stage. The co-benefits are a useful political device for developing alliances with actors who might not be linked explicitly to the environmental agenda. The key aspects of the supranational narratives are:

- Businesses, mostly large corporations, have the potential to lead the transformation to a circular economy at scale;

- Innovations, mostly technological and related to business models, are critical for the transformation to a circular economy;

- Consumers are passive actors who respond to the incentives that are embedded in business models and react in accordance to these incentives;

- There is limited focus on social and political relations of the different actors who are involved in the large-scale transformations. Technology and innovations systems are not embedded in the social and political realities in which the corporations operate. Also, there is limited focus on questioning the fundamental drivers that have led to the throw-away economy and how these would be circumvented by the same actors in their efforts to drive the transformation to a circular economy. It is almost assumed that the enlightened self-interest of the corporation would lead to the transformation to a circular economy;

- As a result of the above, there are limited efforts at questioning the basic economic model that has led to the creation of a throw-away economy. 
Of course, competing narratives question these models on the basis of environmental concerns. Some of these narratives are questioned on the basis of the assumptions while others are more critical of the belief that large corporations can be at the centre stage of the transformation to a circular economy. Several of the assumptions are also questioned on the basis of the lived realities that emerge from the experience of developing countries where waste management is deeply political and the models for closing material cycles are determined to a large extent by social and economic considerations. Even at the supra-national level Global Alliance for Incinerator Alternatives (GAIA), a worldwide alliance of more than eight hundred grassroots groups, NGOs and individuals in over ninety countries, is campaigning against the establishment of incinerators in developing countries (GAIA 2017).

Below we describe some of the national and sub-national level narratives based on our work in India which highlight the possibility of preference of one circular economy approach over another leading to potentially negative impact on the stakeholders involved in the other approach to the circular economy.

\subsection{National Narratives}

In India, a large part of the focus on transformation to close material cycles is inspired by the inability to manage waste effectively. The key campaign of the current government focuses on Cleaning India (MoUD 2017). While there has been a clear failure in effective waste management (Joshi and Ahmed 2016), the narratives of 'zero waste', 'waste to wealth' and 'waste to energy' are extremely powerful and widespread, with significant private sector investor interest following lucrative policies supporting 'waste to energy' through feed-in tariffs (Prasad 2016). By declaring waste as a repository of value (of material resources and energy), it is almost wished that waste would eliminate itself by finding benefactors who are interested in the embedded materials and energy. A large part of the focus on 'waste to wealth' and 'waste to energy' is also driven by the belief that it would draw in the private sector to solve the problems that have thus far have not been effectively dealt with by the public sector. Public-private partnerships are therefore seen as the panacea for managing the waste crisis. The key aspects of the national narrative in India are:

- Large corporations are going to lead the transformation to the waste management problem and could provide the technologies that enable recovery of resources and energy;

- While there are significant overlaps in the supranational and national narratives, there is still no large-scale policy reform that puts resource security and the circular economy at the centre stage of industrial policy;

- The public sector should be involved in creating the right policy environment for the management of waste and provide the incentives to the private sector to perform efficiently and effectively;

- The consumer has been given the moral responsibility by equating cleanliness to godliness. There is limited attention on how consumer behaviour would change without an adequate infrastructure that enables the right behaviour or even encourages the thinking about the convenience of recycling;

- The contestations for materials is acknowledged in the legal framework by invoking the informal sector and appeals at mainstreaming informality but without making any efforts at requisite institutional changes.

Similarly to the international narratives, the national narratives face significant challenges from actors who are involved in shaping policies as well as involved in waste management work in the cities. While there are concerted efforts to generate evidence from international and national experiences about the limitations of waste as a source of energy, the imaginaries of a waste derived energy infrastructure are still pursued with much vigour in the policy circles. For instance, in the case of India even if energy generation potential of entire MSW estimated at around 511 MW (Planning Commission 2014) is achieved less than 10 per cent of Delhi's power demand, which reaches 6,044 MW during summer season, can be met (Press Trust of India 2016). This evidence belies the focus on 'waste to energy' as a 
potential contributor to meeting the energy demand of large cities which has been the basis of media campaigns of several stakeholders. The most critical counter-narratives at the national level in India are all rooted in the environmental challenges of effectively governing the waste to energy infrastructure and questioning the technical appropriateness of such technologies in India.

\subsection{Local Narratives}

At the local level, the prime objective of the citizens, as well as the urban local bodies, is a clean and hygienic environment. There is limited interest in closing material cycles because cities are essentially open systems in a material sense - products enter and leave the boundaries of the city. Also, the boundaries are fairly porous. Closing material cycles for a city government, as a result, is quite challenging.

However, there are significant efforts at closing material cycles within city boundaries, especially in the large metropolitan areas, because this activity creates jobs for significant part of working population. For instance, in Bangalore, several material recovery facilities have been set up to channel the recyclables for effective recovery of embedded resources. In large urban areas waste management provides barrier free entry to the job market and entrepreneurship.

The dominant narrative, however, is not related to jobs but of clean and hygienic cities. For instance, politicians invoke the image of London and Paris as examples of aspirational imageries for city managers. Also, there is a clear focus on involving the private sector, in this case large waste management companies, to provide solutions for waste management. There is a strong belief that the private companies will succeed where the local governments have failed. As we have argued elsewhere (see Chaturvedi and McMurray 2015) there is limited evidence for such faith in the capacities of the private sector to deliver impact, especially in the Indian context.

Due to this tension between privatisation efforts, as well as the job creating potential of waste management (largely in the informal sector), there are quite strong arenas of conflict in both the material and the discursive arenas. The key aspects of the narratives at the city level are:

- Private sector, especially waste management companies, can solve the problem at scale in large cities;

- Technological solutions are likely to play a critical role in achieving progress;

- At the same time, and equally dominant, are the voices of informal actors as well as environmental NGOs that question the environmental performance and appropriateness of technological choices;

- At the city level, there is limited interest amongst the city managers on grand narratives of closing material cycles. They are driven more by the national imaginaries of the zero waste cities, 'waste to wealth' as well as 'waste to energy'.

The recent developments in waste management sector in India is creating uncertainty for the informal sector, while formal large scale companies are being promoted to introduce technology dominated solutions for waste management and recycling (Gidwani and Reddy 2011; Chaturvedi and Gidwani 2011). It is observed that only a few local governments have engaged and worked closely with informal sector actors, while most prefer to work against the informal sector in favour of large private companies (Cavé 2012).

While the technology and private sector-led approach to circular economy dominates, there are emerging models of organising wastepickers, local communities, activist groups etc. that can provide the waste management and recycling without compromising on environmental quality and health. Decentralised small scale, informal sector-led recycling with the support of low-cost solutions provide 
cost effective and socially inclusive alternatives to high-tech, high-cost market led solutions (Demaria and Schindler 2016). 


\section{The Dynamics of Narratives}

In the previous section we characterised the narratives that have emerged at the local, national and supra-national level. But how do certain narratives emerge as the dominant narrative? Our framework allows for responding to such queries by arguing that actor-alliances that converge on certain aspects of closing material cycles enable the development of dominant narratives. Such convergence can happen within a particular level or the alliances can be forged amongst actors at different levels. For instance, the narrative that the private sector can deliver effective waste management solutions largely emerges from the alliance between local governments, formal private sector actors at the local, national and supra-national level as well as policies of the central governments that are rooted in the belief of the ability of private sector to overcome challenges of local governments (see Chaturvedi et al. 2015b). Similarly, the contributions and primacy of the informal sector in waste management in large urban cities is driven by the alliance of civil society organisations, bilateral and multilateral agencies active at several levels. We classify these alliances as intra-level alliances as well as inter-level alliances.

The intra-level alliances are formed when actors with divergent objectives coalesce around specific aspects of a circular economy. For instance, at the local level such alliances can be forged between the local government and the private waste management companies. A competing alliance can be forged between the civil society organisations as well as grass roots movements of the informal sector that advocate for local decentralised solutions using the resourcefulness of the informal sector. At the local level, these contestations could lead to material conflict between the formal and informal waste management service providers, a case which is evident in Delhi. At the national and supra-national level, similar alliances can be formed to influence the national policy processes.

Existing literature as well as the experience of policy-making processes in India clearly suggests that there are significant interactions between the actors that operate at different levels. Also, in certain cases, the same actors operate at different levels making the analysis of the narratives as well as the dynamics quite complex. In order to put order into this complexity, it is critical to analyse the potential alliances that can emerge between actors who are operating at different levels as distinct from intralevel alliances. For instance, the national Government in India as well as in other developing economies are influenced by the best practices abroad when drawing up waste management policies. In some cases, however, the narratives at the supra-national level heavily influence discussions on policy options at the national level and impact the implementation of the policies at the local level. This influence is expected but could be used to explain choice of policies and implementation strategies that might lead to suboptimal outcomes locally. As mentioned above, the focus on 'waste to energy' as a potential win-win situation for waste management as well as solving the energy crisis is a case in point.

While there are possibilities for certain narratives to gain strength due to the forging of intra- and interlevel alliances, as a corollary, it is also clear that certain narratives fade away due to the inability of their proponents to forge such alliances. A clear case in point is the role of the informal sector. In spite of the overwhelming evidence that the informal sector is extremely resourceful and contributes significantly to managing waste as well as in closing material cycles, their role is not at the centre stage of any policy directive at the national level in India. This is evident from the recently announced Waste Management Regulations in India. Although the informal sector is mentioned as a critical actor and there is an acknowledgement of the contributions (WBCSD 2016), the focus of implementation and the incentives are designed in a manner that there is further marginalisation of the informal enterprises.

In certain cases, although the focus of the narrative might be on the same aspect of a circular economy - say closing material cycles - there might be conflicts on the actors who have the potential to drive the change. For instance, at the international level, the discourse on closing material cycles is heavily influenced by the experiences of the now developed economies. As a result, the emerging narratives 
focus on the primacy of the large corporations and private sector entities that are involved in the various stages of closing material cycles, from mining to production, consumption as well as waste management. However, at the local level in developing countries, it is the informal sector that is involved in, not only waste management, but also in repair and refurbishment activities that have significant positive impacts on closing material flows. Our analytical framework suggests that the role of the large corporations is likely to gain traction because of its ability to gain the support of the actors who are operating with similar objectives at the local, national and supranational level, while the role of the informal sector is likely to fade away as the support at the supra-national level might be missing. Table 5.1 below summarises some of the narratives that have emerged due to convergence of narratives at the different levels and others that that emerged due to conflicting narratives.

Table 5.1: Dynamics of Narratives

\begin{tabular}{|l|l|l|}
\hline \multicolumn{1}{|c|}{ Level } & \multicolumn{1}{|c|}{ Synergies across levels } & \multicolumn{1}{c|}{ Conflicts across levels } \\
\hline Supra-national & $\begin{array}{l}\text { Large formal companies as } \\
\text { drivers for closing material cycles }\end{array}$ & $\begin{array}{l}\text { Inability of informal sector models in } \\
\text { closing material cycles }\end{array}$ \\
\hline National & $\begin{array}{l}\text { Technology as a driver for the } \\
\text { transformation to a circular } \\
\text { economy }\end{array}$ & $\begin{array}{l}\text { Informal sector practices are } \\
\text { environmentally unsafe and do not } \\
\text { comply with labour standards }\end{array}$ \\
\hline Local & $\begin{array}{l}\text { Failure of state supported } \\
\text { models }\end{array}$ & $\begin{array}{l}\text { Discrediting of decentralized models } \\
\text { based on the innovations in the } \\
\text { informal sector }\end{array}$ \\
\hline
\end{tabular}

Source: Author's own

\subsection{Power Analysis}

This Section evaluates the reasons for the dominance of market-led narrative which in some cases is leading to the exclusion and/or marginalisation of the informal sector's narrative in developing countries. While some visible reasons for this are well documented in the literature as noted previously, and include the environmental, safety and health implications of the informal sector, there is a need to explore other, often hidden, socio-political causes. As mentioned above, a review of the choice of Circular Economy narratives necessitates an understanding of not only the actors, discourse and narratives but also the power dynamics (Leach et al. 2010: 129; Keeley and Scoones, 2003) which is analysed across different spaces, levels and forms of power (Gaventa 2006). It is argued that despite the emergence of new spaces and opportunities for engaging stakeholders in policy processes, simply creating new institutional arrangements will not necessarily result in greater inclusion or pro-poor policy change. Rather, much will depend on the nature of the power relations that surround and imbue these new, potentially more democratic, spaces. An approach for analysing the spaces, places and dynamics of power, subsequently referred to as 'the power cube' has been developed, based on the argument that power must be understood in relation to how spaces for engagement are created, the levels of power (from local to global), as well as different forms of power across them. A representation of the power cube is provided below, Figure 5.1.

While definition of place is clear as being from local to global level, the term 'space' which is opportunity to participate in the policy making process could either be closed spaces, invited spaces or claimed spaces. Closed spaces are those where decision-making is limited to a selected set of actors without any pretence of broadening the boundaries for inclusion. Invited spaces are created when efforts are made to widen participation, to move from closed spaces to more 'open' ones or 'invited' spaces, i.e. those into which people (as users, citizens or beneficiaries) are invited to participate by various kinds of authorities. Claimed/created spaces are the spaces which are claimed by less powerful actors from or against the power holders, or created more autonomously by them. The power exercised by a stakeholder for the purpose of analysis can be classified as 'Visible Power' that includes the visible and 
definable aspects of political power - the formal rules, structures, authorities, institutions, and procedures of decision making. Hidden Power that involves setting the political agenda by certain powerful people and institutions by controlling who gets to the decision-making table and what gets on the agenda. The third type of power is 'Invisible Power' which involves shaping meaning and what is acceptable (Gaventa 2005). The Power cube analysis is suitable for analysing the dynamics of different circuits of circular economy where, arguably, the formal sector led narrative is dominating while the informal sector is being marginalised. In order to be concrete about the power dynamics, we focus in this Section on e-waste management as a case example of closing material cycles.

Figure 5.1. The Power Cube

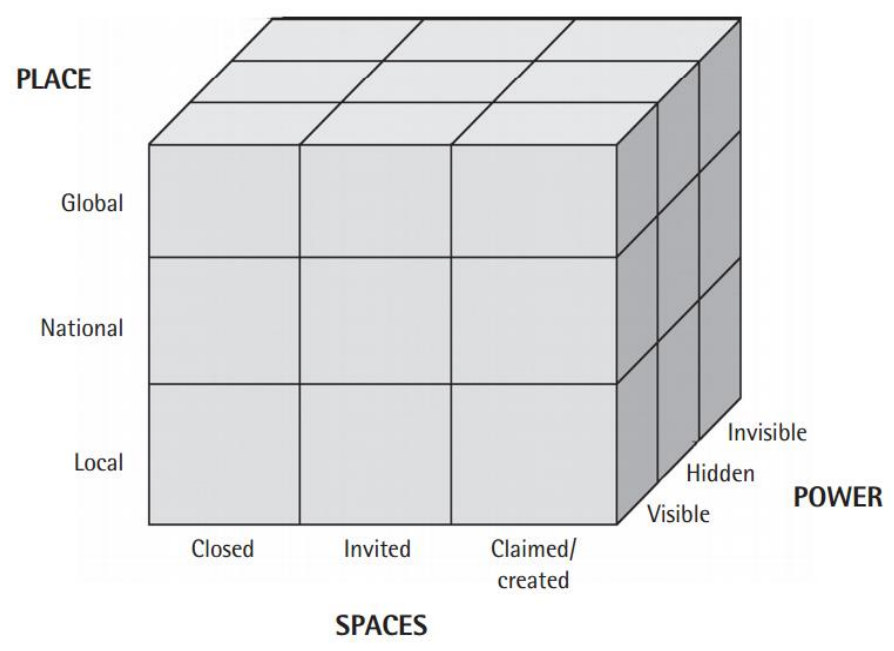

Source: Gaventa 2006, reproduced with the author's permission

The first aspect of the power-cube framework seeks to review spaces as closed, invited or created. These spaces can be evaluated at the local, national and global level. At the national level, Chaturvedi et al. (2010: 3-4) provide an analysis of the policy process for drafting of the e-waste rules, noting a multi-stakeholder based model for agenda setting, policy development and discussion. This national space can be considered as a created space and was formed by particular actors including international, national and local NGOs, industry associations and international agencies such as the United Nations, German Corporation for International Cooperation (GIZ). While the informal recycling sector was engaged in dialogue and consultations, the other key group, reuse and repair enterprises, was not adequately represented and the formal recycling sector gained legitimacy while the informal sector was influenced to engage with the formal sector. Although the national policy space is a created space from the viewpoint of NGOs, international organisations and the private sector, it is an invited space with regard to the varied organisations engaged in the informal sector, and the greater focus on formal recycling has led to lack of acknowledgement of the informal repair, reuse and informal recycling sector.

At the global level formal and private waste management companies dominate the narratives related to environmentally sound management of e-waste. For instance, a 2007 joint statement by a group of international companies and NGOs (Greenpeace 2007) provides an example of the global dynamics wherein financial incentives/market mechanisms are seen as crucial for improvement in formal e-waste management. Some international informal sector initiatives like Global Alliance of Waste Pickers and WIEGO have facilitated recognition of waste collector cooperatives as well as the creation of cooperative owned material recycling facilities, (GlobalRec 2014). However, similar mechanisms for the informal repair and reuse sector are not well developed and are limited for e-waste recyclers.

In the analysis of power at the local level, it is important to recognise both the policy development and implementing agencies. While the policy development process is influenced by actors at local, national 
and international level, the implementation necessarily happens at local level. As a result, at the local level, the actors influential in the material and discursive arenas converge. As documented elsewhere, this creates opportunities for conflict as well as collaboration between the two different pathways, led by the market and the informal sector (Arora et al. 2010). While national level policies including the National Environment Policy, 2006 recognise the need for legal recognition of the informal recycling sector in addition to strengthening their access to finance and technology (WIEGO undated), at the local level varied levels of engagement are visible. However, these opportunities for conflict and cooperation are significantly influenced by actors with significant convening power at the local level, the State Pollution Control Boards responsible for the implementation of the Law as well as the Urban Local Bodies responsible for waste management in the city. Hence, the commitment of the implementing agency at local level influences the engagement of various stakeholders (Toxics Link 2014: 30-47), making access and representation of the informal sector to important decision making bodies at the local level dependent on the priorities of the local implementing agencies.

It is also essential to note the invisible and hidden forms of power that influence the visible discourse and narratives. The presence of ideologies, values and perceptions around waste and the informal sector can be examined through the widely reported and circulated images of the detrimental effects of informal recycling which limit a deeper evaluation of the varied aspects and skills present within the informal sector, including repair and reuse. Combined with the ideas of a centralised and hi-tech space for processing of e-waste, the rudimentary and small shops for repair, reuse or recycle get little emphasis or credit for the key role they are playing in e-waste management in developing countries. This variation in the physical portrayal of the informal sector also influences the circular economy discourse towards more centralised and formal approaches to e-waste. This is noted by Chaturvedi et al. (2015b: 12) as a discrediting of the informal sector, involving 'branding the informal sector as drug addicts, thieves and relics of a pre-modern society who should not be allowed space in a modern world class city'. Additionally for the repair and reuse sector, illegality is a key barrier with the widespread market for counterfeit goods and parts in India. A recent news report noted that the counterfeit electronics market in India is growing at twice the rate of the genuine product market (The Hindu 2014) with Delhi City contributing almost 75 per cent of the trade in counterfeit products (Vikram 2013). Thus distinguishing between the legal and useful operations versus the illegal aspects of informal enterprises also hinders greater recognition and support by local and international actors.

Yet despite these barriers the informal sector continues to exist, which highlights the contrasting dynamics at the local and global levels. Although at the global level there is limited focus on the informal sector contribution to circular economy, at the local level the widespread markets for repair and reuse continue to thrive in a challenging environment. Their local material power through access to e-waste, however, has limited influence on the discourse and dominant framings of a 'Circular Economy' at the national and global levels. These socio-political barriers, hence, inhibit greater inclusivity and opportunities for opening the debate on informal sector's role in the circular economy. The analysis of the actors, interests and narratives including their relative power highlights the need for alliances within and among a group of actors. Additionally partnerships across different levels of local, national and international are noted to be instrumental in supporting the informal and formal recycling sector and similar collaborations in the informal repair and reuse can be critical to opening pathways. 


\section{Conclusion}

The need to close material cycles is well established and widely accepted as a critical contributor to the sustainability of our planet. However, there are multiple pathways to achieve such a process at scale. We argue that several actors with divergent interests are currently involved in shaping the pathways to this possible transformative process. The pathways on which we embark would have material consequences on the economic and social outcomes of those involved. Also, the models that are prioritised for implementation would be selected on the basis of contestations in the material and discursive arenas.

In this paper, we argue that the focus of closing material cycles has to move away from a big business led approach if societies want to transform from a linear to a circular economy. Our proposition is based on the premise that such a transformation is essentially a political process. The focus on a particular actor led model would have to be evaluated for its political feasibility. As a result, in order to develop an analytical lens, we demonstrate that rather than focusing on particular narratives, it is critical to identify the many narratives that emerge from different stakeholders who are involved in this transformative process. We therefore conclude that in order to analytically assess the possibilities of a transformation to a circular economy, it is critical to take an actor-centric approach. We also contend that the actors involved in the transformation to a circular economy are spatially distributed within a city, within a nation state as well as beyond the boundaries of a nation state. As a result, we make the case for analysing narratives at different scales to pin down potential actor constellations that would drive the multiple conceptions of a circular economy. It is clear from the discussion above that the dominant narratives are likely to be those that bundle interests across scales.

We use the conceptual framework to analyse the narratives at the supranational, national and local level. Our analysis is suggestive of a complex relationship between the material and discursive arenas and that circular economy narratives are in a flux at this moment. As a result, it is critical to focus on the politics of circular economy. If evidence based research has to inform conceptions of a circular economy, now is probably the most important juncture to actively pursue the agenda, before the alliances are stabilised and certain narratives emerge as the clear front-runners.

We believe that the unique contribution of this research is two-fold. First, our analytical approach combines for the first time in the literature on circular economy a multi-actor, multi-scale model. This approach allows us to engage with multiple narratives at the local, national and supra-national level. We believe that this approach has the potential to be used in different contexts to examine the case of transformation to a circular economy. Second, our results suggest that contestations in the material and discursive arena in waste management have to be understood beyond the boundaries of an urban agglomeration. The waste management narratives in a large city in India, or for that matter in the United Kingdom, are shaped by actors, not only within the city boundaries, but also in other parts of the world. As a result, solutions that get prioritised must also be evaluated with an analytical lens that incorporates these different influencers. We believe that our approach would allow for the explanation of some of the innocuous choices of solutions, for example the focus on incineration of waste, made by policymakers on effective waste management in India and elsewhere. 


\section{References}

Agarwal, R., Gupta, S. K., Sarkar, P. and Ayushman (2002) 'Recycling Responsibility: Traditional Systems and New Challenges of Urban Solid Waste in India', SRISHTI Report, New Delhi: Toxics Link, http://toxicslink.org/docs/munispalwaste/Recycling\%20Responsibility mail.pdf (21 February 2017)

Annamalai, J. (2015) 'Occupational Health Hazards Related to Informal Recycling of E-waste in India: An Overview' Indian Journal of Occupational and Environmental Medicine, 19.1: 61-65

Arora, R., Chaturvedi, A. and Killguss, U. (2010) 'Environmentally Sound e-Waste Recycling in India: Mainstreaming the informal sector in the formal recycling system', Regional Development Dialogue 31.2: $90-100$

Cave, J. (2012) Urban Solid Waste in Southern Countries: from a Blurred Object to Common Pool Resources, World ISWA Congress, September 2012, Florence, Italy, https://halshs.archivesouvertes.fr/hal-00737461/document (9 November 2017)

Chaturvedi, A. and McMurray, N. (2015) 'China's Emergence as a Global Recycling Hub - What Does it Mean for Circular Economy Approaches Elsewhere?' IDS Evidence Report 146, Brighton: Institute of Development Studies, https://opendocs.ids.ac.uk/opendocs/handle/123456789/6932 (9 November 2017)

Chaturvedi, B. and Gidwani, V. (2011) 'The right to waste: Informal sector recyclers and struggles for social justice in post-reform urban India', pp. 125-153 in India's New Economic Policy: A Critical Analysis, New York NY: Routledge

Chaturvedi, A., Vijayalakshmi, K. and Nijhawan, S. (2015a) Scenarios of Waste and Resource Management: for Cities in India and Elsewhere, IDS Evidence Report 114, Brighton: Institute of Development Studies, https://www.ids.ac.uk/publication/scenarios-of-waste-and-resourcemanagement-for-cities-in-india-and-elsewhere (27 May 2015)

Chaturvedi, A., Arora, R. and Saluja, M. (2015b) 'Private Sector and Waste Management in Delhi: A Political Economy Perspective', IDS Bulletin 46.3: 7-15, Brighton: Institute of Development Studies

Chaturvedi, A., Arora, R. and Ahmed, S. (2010) 'Policy Cycle - Evolution of E-waste Management and Handling Rules' pp.3-4 in National Conference on Sustainable Management of E-waste, http://bit.ly/2heYoBF (9 November 2017)

CSE (2016) Waste Generation In India, New Delhi: Centre for Science and Development (CSE), http://cdn.downtoearth.org.in/library/0.89650700 1463994246 sample-pages.pdf $\quad$ (9 November 2017)

Demaria, F., Schindler, S. (2016) 'Contesting urban metabolism: struggles over waste-to-energy in Delhi, India', Antipode 48: 293-313

EMF (2017) What is a Circular Economy? Cowes: Ellen MacArthur Foundation, https://www.ellenmacarthurfoundation.org/circular-economy (9 November 2017)

Gaventa, J. (2006) 'Finding the Spaces for Change: A Power Analysis', IDS Bulletin 37.6: 23-33

Gaventa, J. (2005) Reflections on the Uses of the 'Power Cube' Approach for Analyzing the Spaces, Places and Dynamics of Civil Society Participation and Engagement, CFP Evaluation Series 2003-2006, No 4, Amsterdam: Mfp Breed Network, http://bit.ly/2yLJ3CW (26 October 2017) 
Gidwani, V. and Reddy, R. N. (2011) 'The Afterlives of "Waste": Notes from India for a Minor History of Capitalist Surplus', Antipode 43.5: 1625-58

GAIA (2017) 'NGT's judgment on Okhla incinerator plant case - A judicial overreach!', on-line: Global Alliance for Incinerator Alternatives, http://www.no-burn.org/why-the-ngt-okhla-order-sets-a-badprecedent-for-indian-environmental-jurisprudence/ (26 October 2017)

GlobalRec (2014) Four pilot projects in the works: an update from the South African Waste Pickers' Association, on-line: Global Alliance of Wastepickers, http://globalrec.org/2014/06/26/four-key-pilotprojects-operating-under-sawpa/ (26 October 2017)

Greenpeace (2007) Joint Statement by a Group of Industry and NGOs on Producer Responsibility for Waste Electrical and Electronic Equipment, Amsterdam: Greenpeace, http://bit.ly/2yJzyoL (26 October 2017)

Joshi, R. and Ahmed, S. (2016) 'Status and challenges of municipal solid waste management in India: A review', Cogent Environmental Science 2: 1139434, http://home.iitk.ac.in/ anubha/H13.pdf (26 October 2017)

Keeley, J. and Scoones, I. (2003) 'Understanding Environmental Policy Processes: A Review', IDS Working Paper 89, Brighton: Institute of Development Studies, http://bit.ly/2jaUWvT (9 November 2017)

Leach, M., Scoones, I. and Stirling, A. (2010) Dynamic Sustainabilities, London: Earthscan

MoUD (2017) Swachh Bharat Urban (Clean India Mission- Urban), New Delhi: Ministry of Housing and Urban Affairs (MoUD), http://www.swachhbharaturban.in/sbm/home/\#/SBM (9 November 2017)

Planning Commission (2014) Report of the Task Force on Waste to Energy (Volume I), New Delhi: Planning Commission, http://planningcommission.nic.in/reports/genrep/rep wte1205.pdf

February 2017)

Prasad, G. P. (2016) 'Waste-to-energy projects see revival in investor interest', LiveMint, 23 March 2016, http://www.livemint.com/Industry/B9q700vtN6YL5jxndS3rjL/Wastetoenergy-projects-see-revival-ininvestor-interest.html (26 October 2017)

Press Trust of India (2016) 'Delhi's Power Demand Breaks Record, Rises To 6044 Megawatt', NDTV, 19 May 2016, http://www.ndtv.com/delhi-news/delhis-power-demand-breaks-record-rises-to-6044megawatt-1408044 (21 February 2017)

Schmitz, H. (2012) 'PEACH Methodology', available through Who Drives Climate Policies in the Rising Powers, Research Project, Brighton: Institute of Developing Studies, https://www.ids.ac.uk/project/who-drives-climate-policies-in-the-rising-powers (22 August 2015)

STEPS (undated) The Pathways Approach of the STEPS Centre, Briefing Note, Brighton: STEPS Centre, http://steps-centre.org/wp-content/uploads/STEPS Pathways online1.pdf (26 October 2017)

The Hindu (2014) 'Counterfeit Electronics Market Growing Twice the Genuine Goods', The Hindu', 17 December 2014, http://bit.ly/1uVgRA9 (9 November 2017)

Toxics Link (2014) 'Time to Reboot', Toxics Link: 20, New Delhi: Toxcis Link, http://toxicslink.org/docs/Time-to-Reboot.pdf (26 October 2017)

Vikram, K. (2013) 'Industry report reveals Delhi contributes 75 per cent to India's booming market in counterfeit goods', Mail OnLine India (16 June 2013), http://dailym.ai/2zRaQzI (22 July 2015) 
WBCSD (2016) Informal approaches towards a circular economy - learning from the plastics recycling sector in India, Geneva: World Business Council for Sustainable Development (WBCSD), http://www.wbcsd.org/Clusters/Circular-Economy/Resources/Informal-approaches-towards-acircular-economy (26 October 2017)

WEF (2017) Shaping the Future of Environment and Natural Resource Security, Geneva: World Economic Forum (WEF), https://www.weforum.org/system-initiatives/environment-and-natural-resourcesecurity (26 October 2017)

WEF (2014) Towards the Circular Economy: Accelerating the Scale-up Across Global Supply Chains, Geneva: World Economic Forum, http://bit.ly/1ro5wei (26 October 2017)

WIEGO (undated) 'Laws \& Policies Beneficial to Waste Pickers', Manchester: Women in Informal Employment: Globalizing and Organizing, http://www.wiego.org/informal-economy/laws-policiesbeneficial-waste-pickers (9 November 2017)

Wilson, D.C. (2007) 'Development drivers for waste management', Waste Management and Research 25: 198-207, http://unpan1.un.org/intradoc/groups/public/documents/apcity/unpan050315.pdf 